most of us oversimplify our explanations of fatigue. If I could paraphrase J.B.S. Haldane, it sometimes seems for too many of us in the sports world that 'Fatigue is not only more complex than we imagine, it is more complex than we can imagine'. This book helps greatly.

Craig Sharp PhD, MRCVS

\section{Exercise Psychology}

Peter Seraganian

Chichester: Wiley-Interscience,

ISBN 047152701 7, 1993, 390 pp.

The field of sport psychology can be divided into two major divisions psychological antecedents of athletic performance and psychological consequences of exercise. The book Exercise Psychology: The Influence of Physical Exercise on Psychological Processes summarizes scientific knowledge about selected aspects of that half of the field concerned with health-related consequences of exercise.

This book has all the strengths and weaknesses of an edited volume. These include, for example, the strength of an experienced researcher writing about a topic that he has been immersed in for many years (e.g. François Péronnet's chapter (with Attila Szabo) concerning sympathetic nervous system responses to acute psychosocial stressors in humans) and the weakness of a lack of consistency in both substance and style across chapters.

The book contains 14 chapters organized into four parts. Part I consists of a single chapter titled 'Historical and conceptual roots of exercise psychology' written by Jack Rejeski and Amy Thompson. Although much of the chapter aptly describes the state of

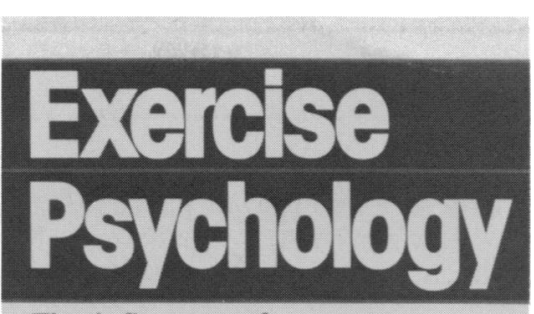

\section{The Influence of}

Physical Exercise on

Psychological Processes

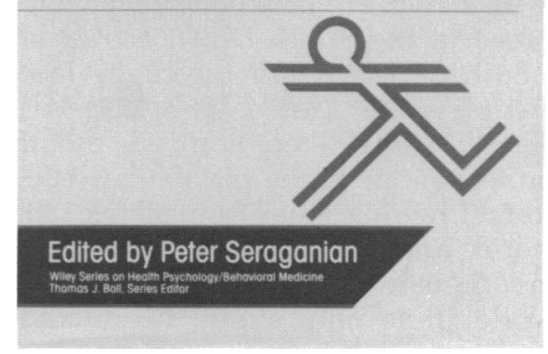

affairs in the field, it also lacks balance by being noncritical about some matters (e.g. results from meta-analyses) and inappropriately critical of other issues.

Part II is titled 'The Status of Relevant Research' and contains chapters by: David Holmes summarizing his research on aerobic. fitness and psychological stress responses (No. 2), Stephen Boutcher describing methods for quantifying aerobic fitness and physical activity (No. 3), Kim Tuson and David Sinyor reviewing the affective consequences of acute aerobic exercise (No. 4), Daniel Landers and colleagues writing about the potential usefulness of meta-analysis in summarizing exercise psychology research (No. 5), Lise Gauvin and Lawrence Brawley proposing alternative methods for the study of exercise and affect (No. 6), François Péronnet and Attila Szabo writing about sympathetic nervous system responses to acute psychosocial stressors (No. 7), and
John Jamieson and Karen Flood who present a chapter that covers basic research methodology issues (No. 8).

Part III is titled 'Applications' and contains chapters by: Roger Fillingim and James Blumenthal about the psychological consequences of exercise in the elderly (No. 9), Lawrence Brawley and Wendy Rodgers about psychosocial aspects of the promotion of activity and fitness at both an individual and community level (No. 10), Thelma Horn and Randal Claytor about the relationship between physical fitness and both self-esteem and reactivity to stressors in children (No. 11), Bonita Long about cognitive aspects associated with emotional responses to exercise (No. 12); and Thomas Plante titled 'Aerobic exercise in the treatment and prevention of psychopathology' (No. 13).

Part IV consists of a single chapter by the editor that overviews the book and addresses selected issues thought to be critical to this area of inquiry. In this chapter it is pointed out that before publication a 2-day conference was held, aimed at promoting coherence across the chapters. Unfortunately, this difficult goal was not achieved.

This book is not comprehensive and in parts there is a lack of accuracy and depth. For example, important topics such as depression, psychoneuroimmunology, eating disorders, and the use and potential of animal models in exercise and mental health research were either ignored or only briefly covered. Despite these shortcomings, this volume has a number of strengths and can be recommended for use in introductory courses, as a single source reference for workers in healthrelated professions who desire information about exercise psychology and as a springboard for further discussion and research dealing with the psychological consequences of exercise.

Patrick J. O'Connor PhD 